\title{
Stress, flourishing and intention to leave of teachers: Does coping type matter?
}

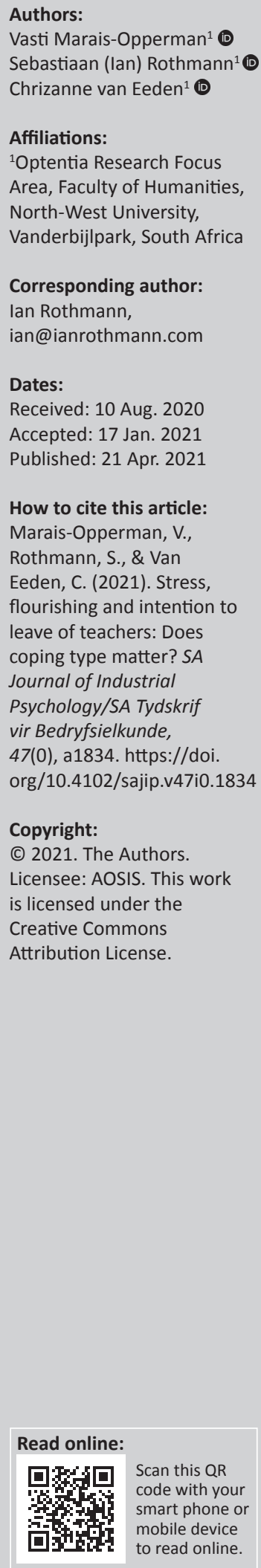

Orientation: Teachers face a demanding work environment which might cause stress. Depending on teachers' coping profile, distress might indirectly affect teachers' intentions to resign from their jobs via their flourishing.

Research purpose: This study aimed to investigate the associations between teachers' perceived stress, flourishing at work, intention to leave their jobs and coping types.

Motivation for the study: The effect of stress on flourishing at work has not been studied in relation to teachers' intentions to leave. Furthermore, no person-centred studies on coping of teachers in relation to their well-being and retention were found.

Research approach/design and method: A sample of teachers $(n=209)$ participated in a crosssectional study. The Perceived Stress Scale, Brief Coping Orientation to Problems Experienced (COPE) Inventory, Flourishing-at-Work Scale - Short Form and Intention to Leave Scale were administered. Latent variable modelling was used to analyse the data.

Main findings: Flourishing at work was positively associated with perceived positive stress and low perceived distress. Perceived distress impacted teachers' intentions to leave directly and indirectly (via low flourishing). Perceived positive stress indirectly and negatively impacted teachers' intentions to leave via flourishing. Person-centred analyses identified three types of copers that were associated with perceived positive stress and distress.

Practical/managerial implications: It is essential to focus on teachers' stress, coping type and flourishing to promote their retention.

Contribution/value-add: This study provided insights regarding the associations between teachers' perceived stress, flourishing at work and intention to leave their jobs. Moreover, it showed that coping types are associated with the perceived stress of teachers.

Keywords: well-being; mental health; coping; stress; intention to leave; teachers.

\section{Introduction}

Growth and stability in South Africa are linked to quality education. According to Cilliers (2020) and Jonas (2019), economic growth in South Africa requires a well-functioning educational system (and capable teachers) that can cope effectively with challenges. However, the quality of education in the country is compromised because of the teaching profession's instability, which results in teachers experiencing overload and a lack of control (Chaaban \& Du, 2017; Schonfeld, Bianchi, \& LuehringJones, 2017). Research (Jackson \& Rothmann, 2006; Janik \& Rothmann, 2016) has shown that secondary school teachers experience high levels of distress caused by a demanding work environment.

Although some South African teachers are coping well with their demands (Nasser, 2015), many teachers think about resigning from their jobs (Baloyi \& Ramose, 2016). Liebenberg and Hattingh (2017) found that 43.9\% of educators in South Africa resigned from their jobs between 2008 and 2013, which implies that retention of teachers is a significant problem. Research by Liebenberg and Hattingh (2017) showed that low morale of teachers is associated with their resignations.

Investing in assessing and promoting individuals' mental health is vital for their motivation, physical health, performance, organisational commitment and retention (Blustein, 2019; Kaufman, 2020; Sisodia \& Gelb, 2019). According to Keyes (2002), mental health ranges from languishing to flourishing. Flourishing exemplifies mental health: individuals who flourish are energetic and function well in different realms of their lives (Keyes \& Haidt, 2003). Languishing individuals do not have diagnosable mental disorders, but they report stagnation, emptiness and despair, even when they might be regarded as successful people (Keyes et al., 2020). 
Although the concept of flourishing has often been studied using context-free measures, few studies have used a measure adapted for work contexts (Rothmann, 2013). Using the Flourishing-at-Work Scale - Short Form (FAWS-SF; Rautenbach \& Rothmann, 2017), Redelinghuys and Rothmann (2020) reported that teachers experience changes in their levels of flourishing over time and that these changes were related to their intention to leave. Stress has not been studied in relation to the flourishing or languishing of teachers using the FAWS-SF. Teachers, who experience distress, might languish rather than flourish, and together stress and a lack of flourishing could affect teachers' intentions to leave (Redelinghuys \& Rothmann 2020). However, limited research evidence exists regarding the associations between teachers' stress, flourishing, coping and intention to leave.

Studies have shown that coping strategies are associated with work engagement (e.g. Rothmann, Jorgensen, \& Marais, 2011) and burnout (Basson \& Rothmann, 2002). When considered in isolation, different coping strategies benefit individual wellbeing. Variable-centred and person-centred approaches can be used to study the effects of coping strategies on teachers' stress and flourishing. Basson and Rothmann (2002) and Rothmann, Van Zyl and Rautenbach (2019) used a variablecentred approach to study coping strategies. A variablecentred approach focuses on the association between variables as they occur on an average in a study population but does not consider differences amongst subpopulations (Caesens et al., 2020). In contrast, person-centred approaches assume that subpopulations of a study population (referred to as latent profiles) are originating from a heterogeneous population (Meyer \& Morin, 2016). Different coping strategies should not be studied in isolation because they might have mutually reinforcing or compensatory effects ( $\mathrm{Ng} \&$ Sorensen, 2008). Little is known about the profiles that characterise the combination of different coping strategies.

\section{Teacher stress}

Kyriacou (2011) distinguished between three approaches to conceptualise teachers' stress, namely, stress because of the demands of their jobs (i.e. workload), stress as emotional and behavioural responses resulting from teachers' jobs and stress as the transaction between teachers' resources and their work demands. Stress arises when individuals cognitively interpret environmental variables as threatening or harmful, affecting their physical health and psychological well-being (Vaughn \& Roesch, 2003). Montgomery and Rupp (2005) defined teacher stress in terms of their experiences of unpleasant, negative emotions, for example, frustration, anxiety, anger, tension and depression associated with work.

Teaching is a stressful occupation (Mansfield, Beltman, S., Broadley, \& Weatherby-Fell, 2016). Travers (2017) analysed the literature and reported that between $25 \%$ and $80 \%$ of teachers found their jobs highly stressful. According to Travers (2017), the Health and Safety Executive in the United Kingdom ranked teaching as the most stressful job. Collie, Perry and Martin (2017) attributed high teacher stress to three factors: leadership support, the relational context and educational policies that affect teaching and learning. Jackson and Rothmann (2006) found that teachers in secondary schools in South Africa experienced high stress because of job demands (e.g. constant change), and a lack of job resources (e.g. a lack of autonomy and control).

A systematic review by Hassard, Teoh, Visockaite, Dewe and Cox (2018) showed that stress is associated with considerable costs ranging from $\$ 221.13$ million to $\$ 187$ billion. About $70 \%-90 \%$ of costs were productivity-related, whilst $10 \%-$ $30 \%$ of costs were associated with healthcare and medical costs. Borman and Dowling (2008) reported that stress is a strong predictor of teachers' turnover.

\section{Flourishing at work}

Stress has been linked to mental health in previous studies (see Schonfeld et al., 2017). However, the association between stress and adverse mental health outcomes (e.g. depression, psychosomatic symptoms and burnout) have mostly been studied. McCarthy et al. (2017) pointed out that research about positive aspects of mental health has been neglected. For Keyes (2003), flourishing exemplifies mental health. According to Keyes (2003), individuals languish when they are devoid of positive emotions towards their life (or work), and they do not function well psychologically or socially (without being depressed in the last year).

Flourishing and languishing occur in work contexts (Keyes, 2007). According to Rothmann et al. (2019, p. 244), flourishing refers to a 'pattern of positive feelings and functioning'. Flourishing is a subjective state characterised by three dimensions, namely, emotional well-being (feeling good about life at work), psychological well-being (becoming a better person at work) and social well-being (contributing things of worth and value to organisations) (Keyes, 2013; Keyes \& Annas, 2009; Rothmann et al., 2019).

Rothmann et al. (2019) distinguished between three dimensions of emotional well-being, namely, job satisfaction, positive affect and negative affect. Job satisfaction, which concerns employees' realisation of wants, refers to evaluating all aspects of a current job in terms of expectations. Positive effect (i.e. pleasant responses, such as joy, gratitude and pride) and negative effect (i.e. unpleasant emotions, such as anger, anxiety and boredom) concern employees' needs satisfaction. Psychological well-being consists of six dimensions: autonomy, relatedness, competence, work engagement, meaningful work and learning (Rothmann et al., 2019). Self-determination theory (Deci \& Ryan, 2011) suggests that the satisfaction of three psychological needs, namely, autonomy (i.e. to experience the freedom of choice at work), competence (to feel efficacious in interacting with the environment) and relatedness (i.e. to experience a sense of belonging and caring), is the condition of psychological wellbeing. Meaningful work (Steger, Dik, \& Duffy, 2012) concerns the subjective experience that one's work is important, contributes to an understanding of the self and the world and 
makes a difference. Work engagement refers to the experience that one is physically involved in tasks, absorbed in work and feels committed to the job and connected to others. Learning entails employees' beliefs that they can develop their abilities and skills to achieve future tasks (Spreitzer, Lam, \& Fritz, 2010). Social well-being at work involves five aspects (Keyes, 1998), namely, social acceptance (i.e. accepting diversity and feeling positive towards it), social actualisation (i.e. valuing the potential of people and institutions), social contribution (i.e. thinking that individuals' daily actions add value to institution), social coherence (i.e. finding social connections understandable and meaningful) and social integration (i.e. feeling integrated into the institution).

Flourishing at work has been positively associated with person-environment fit (Redelinghuys, Rothmann, \& Botha, 2019), advancement as a job resource (Rothmann et al., 2019), as well as self-reported performance, and negatively associated with intention to leave (Redelinghuys et al., 2019).

\section{Coping strategies}

Coping is defined as the cognitive and behavioural strategies that people use to deal with stressors (Lazarus, 1993; Lazarus \& Folkman, 1984). Individuals use coping strategies to manage stressful experiences (Herman, Hickmon-Rosa, \& Reinke, 2018) and to adapt to taxing situations.

Coping entails cognitive responses of individuals to deal with daily problems. These responses aim to manage stress by solving problems, redefining problems, being more adaptable or avoiding stressful situations (Tran, 2016). Stress affects individuals' psychological functioning and negatively influences their well-being and performance (Lazarus \& Folkman, 1984). Coping is an adaptive and stabilising factor that helps individuals to maintain their psychosocial functioning when they experience stress (Moos \& Schaefer, 1993). According to Holahan and Moos (1994), coping involves adaptive strengths that enable individuals to take constructive actions when facing challenges. According to Brown, Westbrook and Challagalla (2005), effective coping makes it possible for individuals to strive for success, solve problems, relieve emotional distress and accomplish their goals. Teachers who cope constructively and adaptively appraise their stress and coping resources realistically, confront problems in an active and task-relevant manner and regulate their emotional reactions to stress (Weiten, 2013).

Montgomery (2017) explored the role of coping in teachers' stress and reported that coping strategies moderated the relationship between stressors and burnout. The research showed that problem-solving and planning (referred to as positive coping strategies) were associated with reduced stress. Negative coping strategies (e.g. as avoidance and disengagement) were associated with higher stress. Teachers who cope effectively by utilising cognitive, emotional and behavioural coping strategies might be capable of adapting to stressful situations, which might lead to flourishing (Nasser, 2015).
Limited research has been conducted regarding coping typologies. Latent profile analysis (LPA), which forms part of a person-centred approach (Spurk, Hirschi, Wang, Valero, \& Kauffeld, 2020), can be used to determine typologies. This is in contrast with a variable-centred model (i.e. a continuous latent variable model). Aldridge and Roesch (2008) applied LPA to adolescents' coping strategies and found three types of copers, namely, active, low generic and avoidance copers. Latent profile analysis provides benefits for studying coping in typologies (Aldridge \& Roesch, 2008). In LPA, similar responses of individuals to observed variables (e.g. coping ways) are analysed to create mutually exclusive profiles.

\section{Intention to leave}

Intention to leave is defined as the desire to stop working for an organisation (Kahumuza \& Schlechter, 2008; Treglown, Zivkov, Zarola, \& Furnham, 2018). It is a crucial determinant of employees' withdrawal behaviour and the final part of their decision-making process about resigning from the job (Griffeth, Hom, \& Gaertner, 2000; Park \& Kim, 2009). The actual turnover of teachers is costly, but it also leads to a loss of job-specific competence and negatively affects the morale of staff members. Research by Barnes, Crowe and Schaefer (2007) showed that the cost of teacher turnover for schools and the education district varied from $\$ 10000$ to $\$ 26502$ per teacher. Watlington, Shockley, Guglielmino and Felsher (2010) suggested that educational departments should invest in teacher retention because such investment reduces turnover and its costs. However, a need also exists for data systems to be designed to make it possible to calculate the costs of teacher turnover.

Research by Baloyi and Ramose (2016) and Liebenberg and Hattingh (2017) confirmed that teacher turnover is a serious concern in South Africa. According to Liebenberg and Hattingh (2017), 43.9\% of teachers who left the profession between 2008 and 2013 resigned. Therefore, the turnover of teachers in South Africa is alarming. A possible way to invest in teachers' retention is to study their intentions to leave (which predict their actual turnover). However, it is also essential to understand the factors that might be related to teachers' intentions to leave. Few studies in emerging economies have explored reasons for teachers' intentions to leave (Lee \& Nie, 2014). More specifically, scientific information is needed to understand the association between teachers' stress, coping strategies, flourishing (vs. languishing at work) and intentions to leave.

\section{Study aims}

This study aimed to investigate the associations between teachers' perceived stress, coping types, flourishing at work and intention to leave their jobs and coping types.

\section{Method Participants}

A convenient sample of teachers from schools in the Gauteng province of South Africa was used. The sample $(n=209)$ included teachers from primary schools $(n=127)$, secondary 
schools $(n=33)$ and special education schools $(n=49)$. The mean age of participants was 41.59 years $(S D=12.35$ years). Teachers' work experience varied from 1 year to 45 years $($ mean $=16.01, S D=11.96)$. Concerning gender, $19.6 \%$ of the participants were men and $80.4 \%$ were women.

\section{Data collection}

The following measuring instruments were used in this study: The Perceived Stress Scale (PSS), the FAWS-SF, the Intention to Leave Scale and the Brief Coping Scale. Participants also completed a biographical questionnaire, which included questions about their gender, education and teaching experience.

The PSS (Cohen \& Williamson, 1988) consists of 10 items that measure how overloaded, unpredictable and uncontrollable respondents find their lives (Cohen \& Williamson, 1988). The PSS includes both positive and negative statements, for example, 'In the last month, how often have you been able to control irritations in your life'? and 'In the last month, how often have you been angered because of things that were outside of your control'? Participants rated the frequency of experience on a five-point Likert scale ranging from 0 (never) to 4 (very often). Research by Hamad, Fernald, Karlan and Zinman (2008) supported the construct validity and reliability of the PSS in South Africa. Regarding the construct validity, Liu et al. (2020) confirmed a two-factor structure for the PSS. The factors are Helplessness (Perceived distress; $\alpha=0.80$ ) and Self-efficacy (Perceived positive stress; $\alpha=0.71$ ).

The Flourishing at Work Scale-Short Form (FAWS-SF; Rautenbach \& Rothmann, 2017) consists of 21 items measuring participants' emotional, psychological and social well-being. Participants responded to the items by indicating how frequently they have experienced emotional well-being (specifically positive affect at work and job satisfaction), psychological wellbeing (including autonomy, competence, relatedness, work engagement, meaningful work and learning) and social wellbeing (including social acceptance, social actualisation, social contribution, social coherence and social integration). An example of an item that measures emotional well-being is: 'During the past month at work, how often did you experience satisfaction with your job?' An example of an item that measures psychological well-being is: 'During the past month at work, how often did you feel confident to think or express your ideas and opinions?' An example of an item that measures social well-being is: 'During the past month at work, how often did you feel that the way your school works makes sense to you?' Participants rated the frequency of their symptoms during the past month on a scale from 1 (never) to 6 (every day). Rautenbach and Rothmann (2017) reported evidence for the construct and convergent validity of the FAWS-SF. A total score or scores for three subscales of flourishing is calculated from individuals' responses. Internal consistencies varying from 0.82 to 0.90 were found for subscales.

The Intention to Leave Questionnaire (ILQ) (Sjöberg \& Sverke, 2000) has three items that measure the intention to leave a job
(Cronbach's alpha coefficient $=0.83$ ). The ILQ was validated by Diedericks (2012) in a South African study.

The BriefCOPE Inventory (BCI; Carver, 1997) consists of 28 items which measure coping strategies (using two items per strategy). The 14 scales are (Carver, 1997) as follows: self-distraction $(\alpha=$ $0.71)$, active coping $(\alpha=0.68)$, denial $(\alpha=0.54)$, substance use $(\alpha=0.90)$, use of emotional support $(\alpha=0.71)$, use of instrumental support $(\alpha=0.64)$, behavioural disengagement $(\alpha=0.65)$, venting ( $\alpha=0.50)$, positive reframing $(\alpha=0.64)$, planning ( $\alpha=$ $0.73)$, humour $(\alpha=0.73)$, acceptance $(\alpha=0.57)$, religion $(\alpha=0.82)$ and self-blame $(\alpha=0.69)$. The participants rated their coping strategies on a scale from 1 (I have not been doing this at all) to 4 (I have been doing this a lot). Using a variable-centred approach, Wang et al. (2018) found support for the factor structure of the BCI but suggested that the 14 coping strategies loaded onto three second-order factors, namely, self-sufficient, avoidant and socially supported coping.

\section{Research procedure}

An ethics committee provided ethical clearance for the study. The provincial education department, school principals and governing bodies at the schools permitted the study. The research team provided information (including their rights as research participants) to teachers. Teachers who were willing to participate in the study signed consent letters. The teachers who participated completed the questionnaires and returned them to the researcher. After that, the data were captured on an Excel spreadsheet.

\section{Data analysis}

Data analyses were conducted using the Mplus 8.4 software program (Muthén \& Muthén, 1998-2020). Confirmatory factor analysis (CFA) was performed using maximum likelihood estimation with robust standard errors (MLR). The goodness of fit of measurement and structural models were assessed using the chi-square value, Tucker-Lewis index (TLI), comparative fit index (CFI), the root mean square error of approximation (RMSEA) and the standardised root mean residual (SRMR). Tucker-Lewis index and CFI values of 0.90 and above indicate an acceptable fit, whilst values above 0.95 indicate a good fit. Root mean square error of approximation and SRMR values lower than 0.08 indicate a close fit between the model and the data (Wang \& Wang, 2020; West, Taylor, \& Wu, 2012). Fit guidelines suggested by Chen (2007) were used to compare models. Changes higher than 0.01 in RMSEA and CFI were regarded as significant. The Akaike information criterion (AIC) and the Bayes information criterion (BIC) were used to compare models (Wang \& Wang, 2020), with lower values, indicating better fit of the model to the data (Kline, 2010).

Reliabilities of scales were computed using a procedure that considers the loading of items on a factor (Raykov, 2009). Statistical Package for the Social Sciences (SPSS) 26 (IBM Corp., 2020) was employed to compute descriptive statistics and analyse the indirect effects of stress on intentions to leave (via teachers' flourishing). We computed indirect effects by using the procedure suggested by Hayes (2018). 
Latent profile analyses using Mplus 8.4 were used to investigate the types of copers (based on seven different coping strategies). Latent profile analyses aim to arrive at an array of latent profiles representing the response patterns in the data and providing information about the prevalence of each latent profile (Wang \& Wang, 2020). The interpretation of latent profiles is based on item-response probabilities. Wang and Wang (2020) and Spurk et al. (2020) suggested that fit statistics, such as the AIC, BIC and sample-size adjusted Bayesian information criterion (ABIC), the Lo-Mendell-Rubin likelihood ratio (LMR LR) test, the adjusted Lo-Mendell-Rubin likelihood ratio (ALMR LR) test and the bootstrap likelihood ratio test (BLRT) are considered to determine the optimal number of profiles. The entropy of a solution provides information about the quality of the latent profile membership classification. The entropy value should be larger than 0.80 . Following the definition of profiles, we investigated how the profile membership relates to covariates. According to Morin, McLarnon and Litalien (2020), covariates should only be included in the analysis after the optimal unconditional profile solution has been obtained. We used the Bolck, Croon and Hagenaars (BCH; Bolck, Croon \& Hagenaars, 2004) method to investigate how the coping profiles relate to covariates (Asparouhov \& Muthén, 2014; Wang \& Wang, 2020).

\section{Results}

We report the results in two parts. Part 1 entails testing the measurement and structural models of stress, flourishing and intention to leave. Part 2 involves the results of latent profile analyses to identify different types of copers and associations of such types with stress, flourishing and intention to leave of teachers.

\section{Part 1}

\section{Testing the measurement model}

Confirmatory factor analysis was used to test a three-factor measurement model and competing models. Items in the questionnaires were used as observed variables. The threefactor model (labelled model 1) consisted of the following variables: (1) perceived distress, a latent variable with six observed variables and perceived positive stress (self-efficacy), a latent variable with four observed variables; (2) flourishing, a higher-order latent variable consisting of three first-order latent variables, namely, emotional well-being (with three observed variables), psychological well-being (with nine observed variables) and social well-being (with five observed variables); (3) intention to leave, a latent variable with three observed variables. We allowed correlations between the latent variables.
Table 1 shows the fit indices of the different measurement models. Model 2 was the same as model 1, except that flourishing was modelled as a single factor rather than three latent variables loading onto a higher-order factor. Also, model 3 was the same as model 1, with the difference that stress was modelled as a single latent variable rather than two latent variables.

Based on the results in Table 1, model 1 fitted the data better than the other models $\left(\chi^{2}=790.17, d f=425, \mathrm{TLI}=0.89\right.$, $\mathrm{CFI}=0.90, \mathrm{RMSEA}=0.06, p<0.01[0.06,0.07]$, SRMR $=0.06)$. Model $2(\triangle \mathrm{AIC}=94.52, \Delta \mathrm{BIC}=84.49)$ and model 3 $(\triangle \mathrm{AIC}=91.05, \Delta \mathrm{BIC}=81.02)$ fitted the data worse than model 1. The increases in AIC and BIC values were higher than 10, the cut-off score for a large difference (Wang \& Wang, 2020). Moreover, the changes in TLI, CFI and RMSEA were higher than 0.01 (Chen, 2007).

However, the fit indices showed some misfit in model 1a. We, therefore, decided to investigate the modification indices (MIs). The MI for item 12 ('... feel that your work makes a difference to the world') and item 13 ('... feel that the work you do serves a greater purpose') of the FAWS-SF was 53.87. We decided to allow the errors of items 12 and 13 to covary (model $1 \mathrm{~b}$ ). Model $1 \mathrm{~b}$ fitted the data better than $(\triangle \mathrm{AIC}=-57.96 ; \Delta \mathrm{BIC}=-54.61)$. The fit indices for model $1 \mathrm{~b}$ showed that further improvement in the model is necessary: $\chi^{2}=739.34, d f=424, \mathrm{TLI}=0.90, \mathrm{CFI}=0.91, \mathrm{RMSEA}=0.06$ $[0.05,0.07] p<0.01, \mathrm{SRMR}=0.06$.

The MI for item 1 ('... feel happy ...') and item 2 ('... feel particularly interested in something') of the FAWS-SF was 19.54. Therefore, we allowed the errors of items 1 and 2 to covary (model 1c). Model 1c fitted the data better than model $1 \mathrm{~b}(\Delta \mathrm{AIC}=-21.32 ; \Delta \mathrm{BIC}=-17.99 ; \Delta \mathrm{TLI}>0.01 ; \Delta \mathrm{CFI}>0.01)$. Model 1c showed a sufficient fit on most of the indices: $\chi^{2}=718.71, d f=423, \mathrm{TLI}=0.91, \mathrm{CFI}=0.92, \mathrm{RMSEA}=0.06$, $p=0.04[0.05,0.07], \mathrm{SRMR}=0.06$.

TABLE 2: Reliability coefficients and correlations for the latent variables $(n=209)$.

\begin{tabular}{lcccc}
\hline Variable & $\boldsymbol{\omega}$ & $\mathbf{1}$ & $\mathbf{2}$ & $\mathbf{3}$ \\
\hline 1. Flourishing at work & 0.96 & - & - & - \\
2. Perceived distress & 0.88 & $-0.49 *^{* *}$ & - & - \\
3. Perceived positive stress & 0.77 & $0.52^{* *_{++}}$ & $-0.68^{* *++}$ & - \\
4. Intention to leave & 0.81 & $-0.75^{* *++}$ & $0.50^{* *++}$ & $-0.43^{* *+}$ \\
\hline$*, p<0.05 ; * *, p<0.01$. & & & &
\end{tabular}

+ , practically significant - medium effect; ++, practically significant - large effect.

TABLE 1: Fit statistics of competing measurement models.

\begin{tabular}{|c|c|c|c|c|c|c|c|c|c|}
\hline Model & $\chi^{2}$ & $d f$ & TLI & CFI & RMSEA & $95 \% \mathrm{Cl}$ & SRMR & AIC & BIC \\
\hline $1 a$ & $790.17 * *$ & 425 & 0.89 & 0.90 & $0.06 * *$ & $0.06,0.07$ & 0.06 & 16793.22 & 17134.14 \\
\hline $1 b$ & $739.34 * *$ & 424 & 0.90 & 0.91 & $0.06 * *$ & $0.05,0.07$ & 0.06 & 16735.26 & 17079.53 \\
\hline $1 c$ & $718.71 * *$ & 423 & 0.91 & 0.92 & $0.06 *$ & $0.05,0.07$ & 0.06 & 16713.94 & 17061.54 \\
\hline 2 & $873.58 * *$ & 428 & 0.87 & 0.88 & $0.07 *$ & $0.06,0.08$ & 0.06 & 16887.74 & 17218.63 \\
\hline 3 & $878.80 * *$ & 428 & 0.86 & 0.88 & $0.07 *$ & $0.06,0.08$ & 0.07 & 16884.27 & 17215.16 \\
\hline
\end{tabular}

$\chi^{2}$, chi-square; $d f$, degrees of freedom; TLI, Tucker-Lewis index; CFI, comparative fit index; RMSEA, root mean square error of approximation; SRMR, standardised root mean square residual; AIC, Akaike information criterion; BIC, Bayes information criterion.

$*, p<0.05 ; * *, p<0.01$. 


\section{Descriptive statistics, reliabilities and correlations}

The descriptive statistics, reliabilities and correlations of the latent variables are reported in Table 2.

Table 2 shows that values higher than the recommended value of 0.70 were obtained. Flourishing at work is statistically significantly and positively related to perceived positive stress (self-efficacy) and negatively related to perceived distress (helplessness) and intention to leave. Perceived distress is statistically significantly and positively related to intention to leave, whilst perceived positive stress is negatively related to intention to leave.

\section{Testing the structural model}

Next, the measurement model was specified as a structural model. The fit indices were as follows: $\chi^{2}=718.69, d f=423$, $p<0.01$; CFI $=0.92$, TLI $=0.91$, RMSEA $=0.06, p=0.05$ $[0.05,0.07] ;$ SRMR $=0.06$. Table 3 shows the standardised regression coefficients, standard errors, estimate divided by the standard error and statistical significance of the variables in the model.

Table 3 shows that perceived positive stress $(\beta=0.34, p<0.01)$ and low perceived distress $(\beta=-0.33, p<0.05)$ predicted flourishing at work $\left(R^{2}=0.30\right)$. Low flourishing $(\beta=-0.68$, $p<0.01)$ and perceived distress $(\beta=-0.21, p<0.05)$ predicted intention to leave $\left(R^{2}=0.59, p<0.01\right)$.

\section{Indirect effects}

Next, we investigated whether work flourishing (mental health) mediates the relationship between perceived stress and intention to leave (Hayes, 2018). Bootstrapping (with 10000 bootstrap samples) was used to construct two-sided bias-corrected $95 \%$ confidence intervals (CIs). The indirect effect is significantly positive (or negative) if the confidence interval does not include zero (Hayes, 2018). The results of the mediation analysis are reported in Table 4.

Table 4 shows that perceived positive stress $(\beta=-0.23[-0.06$, $-0.43], p<0.01)$ indirectly and negatively affected intention to leave via flourishing at work. Perceived distress indirectly

TABLE 3: Standardised regression coefficients.

\begin{tabular}{llcccc}
\hline Dependent variable & Independent variable & $\boldsymbol{b}$ & $\mathrm{SE}$ & Est/SE & $\boldsymbol{P}$ \\
\hline Flourishing & Perceived positive stress & 0.34 & 0.12 & 2.90 & $0.00^{* *}$ \\
& Perceived distress & -0.26 & 0.11 & -2.30 & $0.02^{*}$ \\
Intention to leave & Flourishing & -0.68 & 0.07 & -9.31 & $0.00^{* *}$ \\
& Perceived positive stress & 0.17 & 0.10 & 0.65 & 0.52 \\
& Perceived distress & 0.21 & 0.09 & 2.30 & $0.02^{*}$ \\
\hline
\end{tabular}

Est, estimate; $\mathrm{SE}$, standard error.

$*, p<0.05 ; * *, p<0.01$.

TABLE 4: Indirect effects of stress on intention to leave via flourishing.

\begin{tabular}{lccc}
\hline Variable & \multicolumn{3}{c}{ Intention to leave } \\
\cline { 2 - 4 } & $\boldsymbol{B}$ & $\mathbf{S E}$ & $\mathbf{9 5 \%} \mathbf{C l}$ \\
\hline Perceived distress & 0.18 & 0.07 & $0.06,0.34$ \\
Perceived positive stress & -0.23 & 0.09 & $-0.43,-0.06$ \\
\hline
\end{tabular}

$\mathrm{SE}$, standard error; $\mathrm{Cl}$, confidence interval. and positively affected intention to leave $(\beta=0.18[0.06,0.34]$, $p<0.01$ ) via languishing at work.

\section{Part 2}

\section{Latent profiles of coping strategies}

Exploratory factor analysis using Mplus 8.4 (Muthén \& Muthén, 1998-2020) was performed to identify factors from the 28 items of the BCI that could be used in latent profile analyses of coping strategies. The results showed that seven factors with eigenvalues larger than 1 could be extracted. The following fit statistics were obtained for the seven-factor model of coping strategies: $\chi^{2}=212.39, d f=164, p<0.01$; $\mathrm{CFI}=0.98, \mathrm{TLI}=0.95, \mathrm{RMSEA}=0.04, p=0.93[0.02,0.05]$; $\mathrm{SRMR}=0.03$. The model fitted the data well, except for the chi-square value. The following factors were extracted: (1) active coping (consisting of positive reframing, active coping and planning; $\alpha=0.85$ ); (2) denial and disengagement ( $\alpha=0.72)$; (3) instrumental and emotional social support ( $\alpha=0.85)$; (4) substance use $(\alpha=0.92)$; (5) humour $(\alpha=0.79)$; (6) self-blame $(\alpha=0.75)$ and (7) Venting $(\alpha=0.57)$.

Latent profile analyses were carried out on participants' responses to the seven dimensions of the $\mathrm{BCI}$ as identified by exploratory factor analyses. Given the recommendation that the best log-likelihood value should replicate in at least two final stage solutions (Spurk et al., 2020, p. 10), we initially set the random starts of all the models to 300 with 10 optimisation phases. As recommended by Wang and Wang (2020), we increased the random starts 10 times to 3000 with 100 optimisation phases to check whether the findings were the same. Table 5 shows the fit indices.

The fit indices show significantly better fit for Profile 3 compared with Profile $2(\triangle \mathrm{AIC}=203.44, \Delta \mathrm{BIC}=176.70$ and $\triangle \mathrm{ABIC}=202.05)$. The LMR LR $(p<0.05)$, ALMR $(p<0.05)$ and BLRT $(p<0.01)$ for Profile 3 are all statistically significant. The fit statistics for Profile 4 are acceptable. However, the plots of AIC and BIC values support three rather than four profiles because there was little change between the AIC and BIC values of the 3- and 4-class solutions (see Figure 1).

The entropy value of model 3 was 0.97 , which suggests good profile verification (Wang \& Wang, 2020). Individuals were profiled with high certainty in the most likely latent profile: 1.00 (Profile 1), 0.94 (Profile 2) and 1.00 (Profile 3). The latent profiles are illustrated in Figure 2.

TABLE 5: Comparison of different latent profile models.

\begin{tabular}{lcccccc}
\hline Model & AIC & BIC & ABIC & LMR LR test $(p)$ & ALMR LR $(p)$ & BLRT $(p)$ \\
\hline 1 Profile & 3335.46 & 3382.25 & 3337.89 & - & - & - \\
2 Profiles & 3172.95 & 3246.48 & 3176.77 & $0.0006 * *$ & $0.0007 * *$ & $0.0000 * *$ \\
3 Profiles & 2969.51 & 3069.78 & 2974.72 & 0.0382 & 0.0410 & $0.0000 * *$ \\
4 Profiles & 2888.15 & 3015.16 & 2894.76 & 0.0632 & 0.0672 & $0.0000 * *$ \\
\hline
\end{tabular}

AIC, Akaike information criterion; BIC, Bayesian information criterion; $A B I C$, adjusted Bayesian information criterion; LMR LR, Lo-Mendell-Rubin test; ALMR LR, adjusted Lo-Mendell-Rubin test; BLRT, bootstrapped likelihood ratio test.

$* *, p<0.01$ 


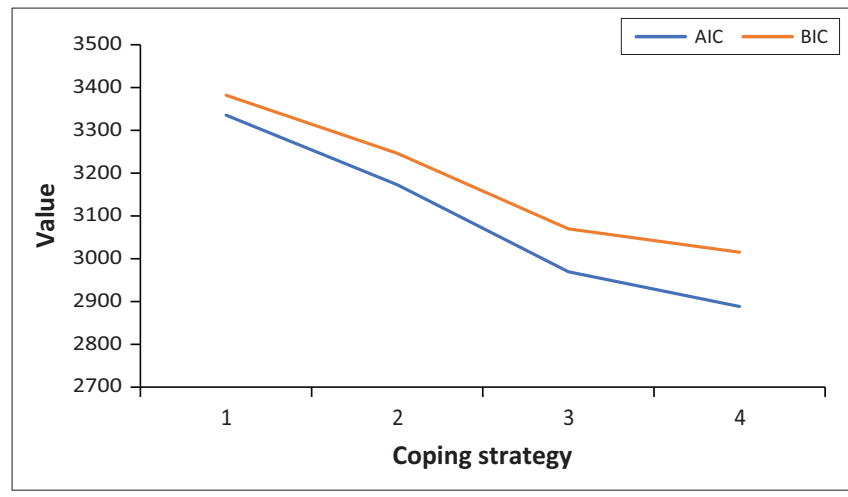

AIC, Akaike information criterion; BIC, Bayes information criterion.

FIGURE 1: Plots of the Akaike information criterion and the Bayes information criterion values.

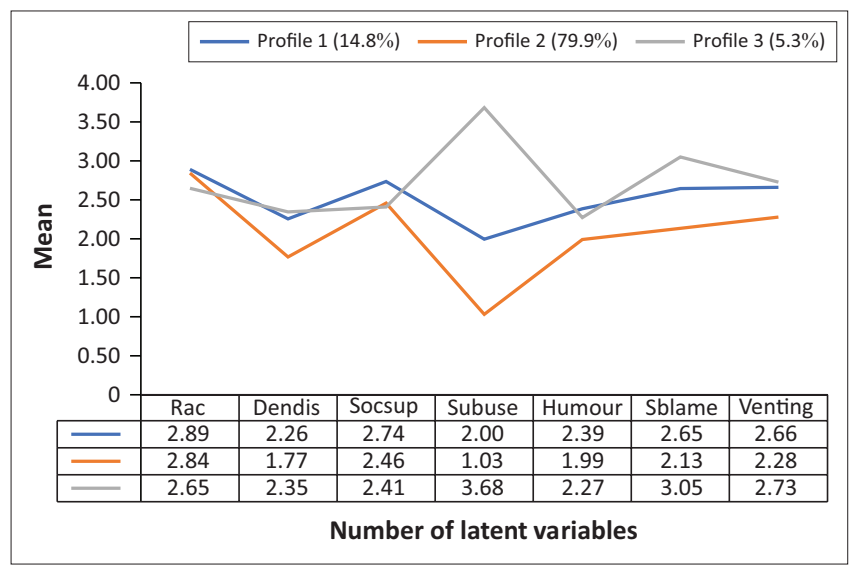

RAC, Positive reframing and active coping; DENDIS, denial and disengagement; SOCSUP, instrumental and emotional social support; SUBUSE, substance use; SBLAME, self-blame; VENTING, venting of emotions.

FIGURE 2: Profiles of different types of copers.

Three coping types were identified. The first profile (avoidance copers) comprised 14.83\% $(n=31)$ of the participants. Individuals in Profile 1 used active coping strategies, but they also engaged in avoidance strategies (denial, venting of emotions and self-blame). The second profile (active copers) comprised 80\% $(n=167)$ of the participants. Individuals in Profile 2 engaged mainly in active coping strategies (i.e. reinterpretation, active coping and social support). Active copers engaged much less in avoidance coping (substance abuse, denial and disengagement and venting of emotions). The third profile (passive destructive copers) comprised $5.27 \%(n=11)$ of the participants. Individuals in Profile 3 engaged in avoidance strategies (denial, venting of emotions and self-blame), but they measured especially high in substance use and self-blame.

Next, the differences between the stress, flourishing and intentions to leave of the three types of copers were analysed. The chi-square values of two distal variables, namely, flourishing at work $\left(\chi^{2}=3.29, d f=2, p=0.19\right)$ and intention to leave $\left(\chi^{2}=5.11, d f=2, p=0.07\right)$ were not statistically significant. The chi-square values of two distal variables, namely, perceived distress $\left(\chi^{2}=32.09, d f=2, p<0.01\right)$ and perceived positive stress $\left(\chi^{2}=21.54, d f=2, p<0.01\right)$ were statistically significant. Concerning perceived distress, the comparison of

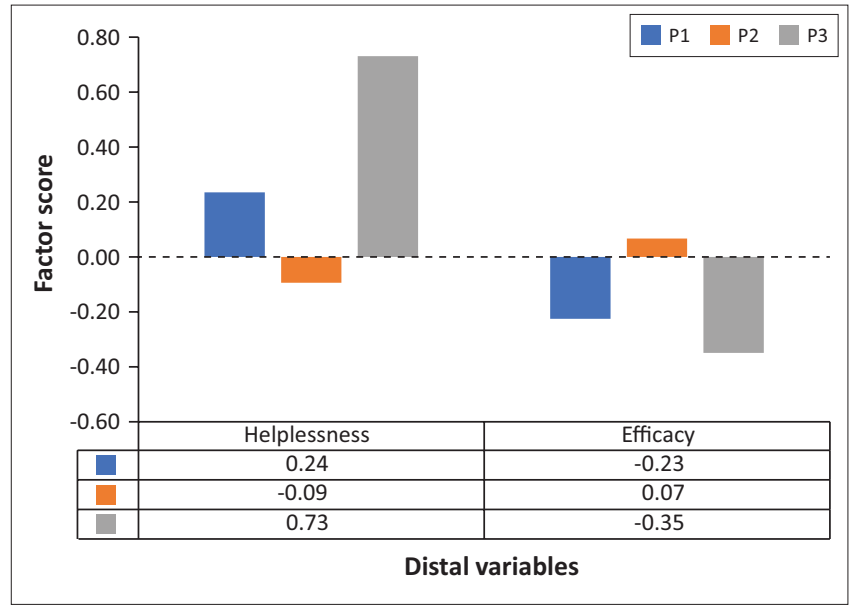

FIGURE 3: Perceived distress and positive stress factor scores of different copers.

profiles showed that Profile 2 (active copers) experienced statistically significantly lower scores than passive destructive copers $\left(\chi^{2}=7.88, d f=2, p<0.01\right)$ and avoidance copers $\left(\chi^{2}=\right.$ $27.77, d f=2, p<0.01)$. Avoidance copers reported statistically significantly less perceived distress than passive destructive copers $\left(\chi^{2}=7.44, d f=2, p<0.01\right)$. Concerning positive stress, the comparison of profiles showed that active copers experienced statistically significantly higher positive stress than passive destructive copers $\left(\chi^{2}=9.73, d f=2, p<0.01\right)$. Furthermore, active copers experienced statistically significantly higher positive stress than avoidance copers $\left(\chi^{2}=14.23, d f=2, p<0.01\right)$. Figure 3 shows the scores between the two distal variables that differed statistically significantly between the three coping types.

\section{Discussion}

This study focused on the relationship amongst teachers' flourishing at work, coping type, perceived stress and intention to leave their jobs. The results provide evidence that low perceived distress (helplessness) and high positive stress (self-efficacy) were positively associated with teachers' flourishing. Teachers who experienced distress and who did not flourish were inclined to think of leaving their jobs. Flourishing was the best predictor of not having intentions to leave. Furthermore, both perceived distress and positive stress impacted intention to leave indirectly via flourishing. Finally, latent profile analyses provided support for three types of copers: active, avoidance and passive destructive copers. Membership of the three coping profiles was significantly associated with perceived distress and positive stress.

The results showed that low perceived distress (helplessness) and high perceived positive stress (self-efficacy) predicted flourishing at work. Teachers who perceived the demands that they must deal with as manageable felt and functioned well at work (Antonovsky, 1987; Frazier, 2002; Tugade \& Fredrickson, 2004). Concerning perceived distress, teachers who perceive their jobs as overdemanding will be inclined to languish at work (Goddard \& Goddard, 2006; Seery, Holman, \& Silver, 2010). 
Teachers who did not flourish (compared to those who flourished) were more inclined to think of leaving their jobs. The effect of low flourishing on the intention to leave was reinforced by perceived distress. Research by Skaalvik and Skaalvik (2011), Goddard and Goddard (2006) and Barling, Kelloway and Frone (2005) also showed that mental health and stress impacted individuals' intentions to leave. Intention to leave might be part of a flight response from teachers' distress (McCarthy, 2007; Weiten, 2013). Perceived distress indirectly impacted teachers' intentions to leave via low flourishing at work, whilst positive stress impacted their intentions to leave negatively via flourishing.

Seven coping strategies, namely, active coping (which included positive reframing, active coping and planning), denial and disengagement, instrumental and emotional social support, substance use, humour, self-blame and venting of emotions, were extracted using exploratory factor analysis. Using a categorical latent variable model (i.e. person-centred analysis), we found three types of copers, namely, active copers ( $80 \%$ of participants), avoidance copers $(14.83 \%)$ and passive destructive copers (5.27\%). Teachers who were classified as active copers engaged in active coping (which included positive reframing, taking action and planning), but low mean scores on avoidance and selfdestructive behaviours (e.g. denial and disengagement, substance use, self-blame and venting of emotions) also characterised them. Avoidance copers engaged in active coping and seeking social support, but they were inclined to use avoidance strategies (denial and disengagement, venting of emotions and self-blame). Passive destructive copers engaged in active coping strategies and avoidance strategies, but they measured higher than the other coping types regarding substance use and self-blame.

The active coping type that emerged from the latent profile comprised the largest part of the sample and was the most adaptive type in terms of distress. The results showed that active copers experienced significantly lower distress than passive destructive as well as avoidance copers. Moreover, avoidance copers reported statistically significantly less distress than passive destructive copers. The comparison of profiles showed that active copers experienced significantly higher positive stress than avoidance and passive destructive copers. These findings confirm the findings of Aldridge and Roesch (2008) with adolescents. Active copers did not only show constructive coping strategies such as positive reframing, planning and active coping, but also used avoidance coping strategies, though to a lesser degree. Active copers specifically scored lower on three coping strategies, namely, substance use, denial and disengagement, and venting of emotions. These findings indicate that active copers adaptively used their coping repertoire.

Avoidance copers seem to be better adjusted in terms of experiences of perceived distress compared to passive destructive copers, but less well-adjusted than active copers, in terms of perceived distress as well as positive stress. Avoidance copers used active coping strategies and social support as coping strategies, but they were more inclined to use coping strategies such as denial and disengagement than active copers, and less inclined than passive destructive copers to use substances as a coping strategy.

Teachers within the passive destructive type were poorly adjusted compared to the other two coping types. Passive destructive copers showed higher perceived distress (helplessness) and lowered positive stress (self-efficacy) than active copers. Although passive destructive copers also used reframing, planning and active coping strategies, they were more inclined to use coping strategies such as substance use, self-blame and denial and disengagement than the active coping type. Therefore, the coping repertoire that the passive destructive coping type used was less adaptive.

Coping types were not statistically significantly related to flourishing or languishing or intention to leave in this study. However, this finding can be explained by the high standard errors and a small sample size of the passive destructive coping type. An analysis of mean scores on flourishing and intention to leave suggested that active copers measured substantially higher on flourishing and lower on intentions to leave than passive destructive copers.

According to Tomasulo (2020), passivity in response to stress is not learnt. It is the default unlearned response to prolonged aversive events, which in turn inhibits escape. The focus should be on looking forward to develop strategies to learn control, rather than looking back to unlearn what has happened. Distress causes people to be anxious and passive by default. When something bad happens, teachers might withdraw to save energy for bad times. Therefore, focusing on ways to detect and expect control creates hope.

Research (Aspinwall, 2011; Folkman \& Moskowitz, 2004; Park, 2011; Taylor, 2011) has shown the beneficial effects of active coping strategies on promoting stress resistance and mental health. Prolonged and severe stress might result in 'giving up and blaming oneself' behaviour (Weiten, 2013, p. 547). Passivity and feeling a lack of control are the default automatic, unlearned response to prolonged adversity. To reduce distress, individuals must learn the perception that they can control and harness their environment's unpredictability (Maier \& Seligman, 2016). Individuals who score high on self-control scales know how to form habits, and they have automated the experience so that they do not need to rely only on self-control (Tomasulo, 2020).

\section{Limitations and recommended future research}

This study had various limitations. Firstly, a survey was used in this study, which implies that causal relations between variables cannot be claimed. Experimental studies are needed to investigate whether distress can be reduced through constructive coping strategies. The intervention could focus on individuals' capabilities to control and harness the unpredictability in their environment. Secondly, we used a 
convenient sample in this study, and the sample size was relatively small. Therefore, we do not claim that our findings are generalisable to other teachers. In future studies, larger and representative samples should be used. Thirdly, we used only self-report measures in this study. Common method bias might, therefore, affect the validity of our findings. However, according to Johnson, Rosen and Djurdjevic (2011), common method variance is seldom sufficiently strong to affect the findings' validity. Lastly, we modelled perceived stress in terms of two factors. According to Cohen (1988), the distinction between two factors might reflect item directionality. Consequently, subscale scores should be used with caution.

The effect of positive reframing and active coping on teachers' perceived distress, self-efficacy, flourishing at work and intention to leave should be studied. Research is also necessary regarding how teachers could use personal control strategies (and not revert to avoidance, denial and self-blame coping strategies in stressful situations).

\section{Conclusion}

Based on the results of this study, we conclude that stress affects teachers' positive functioning and feeling. Perceived distress (helplessness) was associated with teachers' tendency to languish at work, whilst perceived positive stress (selfefficacy) contributed to flourishing at work. Mental health (as flourishing) and perceived distress affected teachers' intentions to leave. It is essential to plan and implement interventions to facilitate teachers' mental health and deal with distress.

This study also sought to identify teachers' coping typologies and their associations with stress, flourishing and intention to leave. Three opting types emerged from the LPA. The coping repertoires used by the three coping types explained how adaptive teachers were in dealing with stress. Active copers adapted well, avoidance copers adapted less well, whilst passive destructive copers adapted poorly to stress. Therefore, to reduce perceived stress (helplessness) and promote positive stress (self-efficacy), it is vital to promote the use of an appropriate repertoire of coping strategies.

\section{Acknowledgements Competing interests}

The authors declare that they have no financial or personal relationships that may have inappropriately influenced them in writing this research article.

\section{Authors' contributions}

V.M-O. and S.R. and C.v.E. contributed equally to this article.

\section{Ethical considerations}

Ethical approval to conduct this study was obtained from the Humanities and Health Research Ethics Committee (HHREC) of North-West University (clearance no. NWU-HS-2017-0061).

\section{Funding information}

This research received no specific grant from any funding agency in the public, commercial or not-for-profit sectors.

\section{Data availability}

The data that support the findings of this study are available from North-West University.

\section{Disclaimer}

The views and opinions expressed in this article are those of the authors and do not necessarily reflect the official policy or position of any affiliated agency of the authors.

\section{References}

Aldridge, A.A., \& Roesch, S.C. (2008). Developing coping typologies of minority adolescents: A latent profile analysis. Journal of Adolescence, 31(4), 499-517. https://doi.org/10.1016/j.adolescence.2007.08.005

Antonovsky, A. (1984). The sense of coherence as a determinant in health. In J.D. Matarazzo (Ed.), Behavioral health: A handbook of health enhancement and disease prevention (pp. 114-129). New York, NY: John Wiley.

Asparouhov, T., \& Muthén, B.O. (2014). Auxiliary variables in mixture modeling: Three-step approaches using Mplus. Structural Equation Modeling, 21(3), 329-341. https://doi.org/10.1080/10705511.2014.915181

Aspinwall, L.G. (2011). Future-oriented thinking, proactive coping and the management of potential threats to health and well-being. In S. Folkman (Ed.), The Oxford handbook of stress, health and coping (pp. 334-365). Oxford University Press.

Baloyi, L., \& Ramose, M.B. (2016). Psychology and psychotherapy redefined from the viewpoint of the African experience. Alternation Journal, 18, 12-35.

Barling, J., Kelloway, E.K., \& Frone, M.R. (2005). Handbook of work stress. Thousand Oaks, CA: Sage.

Barnes, G., Crowe, E., \& Schaefer, B. (2007). The cost of teacher turnover in five school districts: A pilot study. Retrieved from http://www.eric.ed.gov/ERICDocs/data/ ericdocs2sql/content_storage_01/0000019b/80/2a/49/03.pdf

Basson, M.J., \& Rothmann, S. (2002). Sense of coherence, coping and burnout of pharmacists. South African Journal of Economic and Management Sciences, 5(1), 35-62. https://doi.org/10.4102/sajems.v5i1.2664

Blustein, D.L. (2019). The importance of work in an age of uncertainty: The eroding work experience in America. New York, NY: Oxford University Press.

Bolck, A., Croon, M.A., \& Hagenaars, J.A. (2004). Estimating latent structure models with categorical variables: One-step versus three-step estimators. Political Analysis, 12(1), 3-27. https://doi.org/10.1093/pan/mph001

Borman, G.D., \& Dowling, N.M. (2008). Teacher attrition and retention: A metaanalytic and narrative review of the research. Review of Educational Research, 78(3), 367-409. https://doi.org/10.3102/0034654308321455

Brown, S.P., Westbrook, R.A., \& Challagalla, G. (2005). Good cope, bad cope: adaptive and maladaptive coping strategies following a critical negative work event. Journal of Applied Psychology, 90(4), 792-798. https://doi.org/10.1037/0021-9010.90.4.792

Caesens, G., Gillet, N., Morin, A.J.S., Houle, S.A., \& Stinglhamber, F. (2020). A personcentred perspective on social support in the workplace. Applied Psychology: An International Review, 69(3), 686-714. https://doi.org/10.1111/apps.12196

Carver, C.S. (1997). You want to measure coping but your protocols too long: Consider the Brief COPE. International Journal of Behavioral Medicine, 4(1), 92-100. https://doi.org/10.1207/s15327558ijbm0401_6

Chaaban, Y., \& Du, X. (2017). Novice teachers' job satisfaction and coping strategies: Overcoming contextual challenges at Qatari government schools. Teaching and Teacher Education, 67, 340-350. https://doi.org/10.1016/j.tate.2017.07.002

Chen, F.F. (2007). Sensitivity of goodness of fit indexes to lack of measurement invariance. Structural Equation Modeling: A Multidisciplinary Journal, 14(3), 464-504. https://doi.org/10.1080/10705510701301834

Cilliers, J. (2020). Africa first: Igniting a growth revolution. Johannesburg/Cape Town: Jonathan Ball Publishers.

Cohen, S. (1988). Perceived stress in a probability sample of the United States. In S. Spacapan \& S. Oskamp (Eds.), The Claremont Symposium on applied social psychology. The social psychology of health (pp. 31-68). Thousand Oaks, CA: Sage.

Cohen, S., \& Williamson, G. (1988). Perceived stress in a probability sample of the United States. In S. Spacapam \& S. Oskamp (Eds.), The social psychology of health: Claremont Symposium on applied social psychology (pp. 31-67). Newbury Park, CA: Sage.

Collie, R.J., Perry, N.E., \& Martin, A.J. (2017). School context and educational system factors impacting educator stress. In T.M. McIntyre, S.E. Mclntyre, \& D.J. Francis (Eds.) Educator stress: An occupational health perspective (pp. 3-22). Cham: Springer.

Deci, E.L., \& Ryan, R.M. (2011). Levels of analysis: Regnant causes of modeling and well-being: The role of psychological needs. Psychological Inquiry, 22(1), 17-22. https://doi.org/10.1080/1047840X.2011.545978 
Diedericks, E. (2012). Flourishing of employees in the information technology industry in South Africa. Unpublished doctoral thesis. Vanderbijlpark: North-West University.

Folkman, S., \& Moskowitz, J.T. (2004). Coping: Pitfalls and promise. Annual Review of Psychology, 55, 745-774. https://doi.org/10.1146/annurev.psych.55. 090902.141456

Frazier, L.D. (2002). Stability and change in patterns of coping with Parkinson's disease. The International Journal of Aging and Human Development, 55(3), 207-231. https://doi.org/10.2190/UA78-79LB-4GCF-8MJT

Goddard, R., \& Goddard, M. (2006). Beginning teacher burnout in Queensland schools: Associations with serious intentions to leave. The Australian Educational Researcher, 33(2), 61-75. https://doi.org/10.1007/BF03216834

Griffeth, R.W., Hom, P.W., \& Gaertner, S. (2000). A meta-analysis of antecedents and correlates of employee turnover: Update, moderator tests, and research implications for the next millennium. Journal of Management, 26(3), 463-488. https://doi.org/10.1177/014920630002600305

Hamad, R., Fernald, L.C.H., Karlan, D.S., \& Zinman, J. (2008). Social and economic correlates of depressive symptoms and perceived stress in South African adults. Journal of Epidemiology and Community Health, 62(6), 538-544. https://doi. org/10.1136/jech.2007.066191

Hassard, J., Teoh, K.R.H., Visockaite, G., Dewe, P., Cox, T. (2018). The cost of workrelated stress to society: A systematic review. Journal of Occupational Health Psychology, 23(1), 1-17. https://doi.org/10.1037/ocp0000069

Hayes, A.F. (2018). Introduction to mediation, moderation, and conditional process analysis: A regression-based approach (2nd edn.). New York, NY: The Guilford Press.

Herman, K.C., Hickmon-Rosa, J., \& Reinke, W.M. (2018). Empirically derived profiles of teacher stress, burnout, self-efficacy, and coping and associated student outcomes. Journal of Positive Behavior Interventions, 20(2), 90-100. https://doi. org/10.1177/1098300717732066

Holahan, C.J., \& Moos, R.H. (1994). Life stressors and mental health: Advances in conceptualizing stress resistance. In W.R. Avinson \& I.H. Godlib (Eds.), Stress and mental health: Contemporary issues and prospects for the future (pp. 213-238).
New York, NY: Plenum.

IBM Corp. (2020). IBM SPSS statistics: Version 26. Armonk, NY: IBM Corp.

Jackson, L.T.B., \& Rothmann, S. (2006). Occupational stress, organisational commitment and ill-health of educators in the North West Province. South African Journal of Education, 26(1), 75-95.

Janik, M., \& Rothmann, S. (2016). Work engagement of secondary school educators in Namibia: The effects of the relational context and psychological conditions. Journal of Psychology in Africa, 26(4), 316-325. https://doi.org/10.1080/1433023 7.2016.1208921

Johnson, R., Rosen, C., \& Djurdjevic, E. (2011). Assessing the impact of common method variance on higher-order multidimensional constructs, Journal of Applied Psychology, 96(4), 744-761. https://doi.org/10.1037/a0021504

Jonas, M. (2019). After dawn: Hope after state capture. Johannesburg: Pan Macmillan.

Kahumuza, J., \& Schlechter, A.F. (2008). Examining the direct and some mediated relationships between perceived support and intention to quit. Managemen Dynamics: Journal of the Southern African Institute for Management Scientists, $17(3), 2-19$.

Kaufman, S.B. (2020). Transcend: The new science of self-actualization. New York, NY: Penguin.

Keyes, C.L.M. (1998). Social well-being. Social Psychology Quarterly, 61(2), 121-140. https://doi.org/10.2307/2787065

Keyes, C.L.M. (2002). The mental health continuum: From languishing to flourishing in life. Journal of Health and Social Behavior, 43(2), 207-222. https://doi. org/10.2307/3090197

Keyes, C.L.M. (2003). Complete mental health: An agenda for the 21st century. In C.L.M. Keyes \& J. Haidt (Eds.), Positive psychology and the life well lived (pp. 293-312). Washington, DC: American Psychological Association. https://doi. org/10.1037/10594-013

Keyes, C.L.M. (2007). Promoting and protecting mental health as flourishing. A complementary strategy for improving national mental health. American Psychologist, 62(2), 95-108. https://doi.org/10.1037/0003-066X.62.2.95

Keyes, C.L.M. (2013). Protecting and promoting positive mental health: Early and often throughout the lifespan. In C.L.M. Keyes (Ed.), Mental well-being: International contributions to the study of positive mental health (pp. 3-28). New York, NY: Springer.

Keyes, C.L.M., \& Annas, J. (2009). Feeling good and functioning well: Distinctive concepts in ancient philosophy and contemporary science. Journal of Positive Psychology, 4(3), 197-201. https://doi.org/10.1080/17439760902844228

Keyes, C.L.M., \& Haidt, J. (2003). Flourishing: Positive psychology and the life welllived. Washington, DC: American Psychological Association.

Keyes, C.L.M., Yao, J., Hybels, C.F., Milstein, G., \& Proeschold-Bell, R.J. (2020). Are changes in positive mental health associated with increased likelihood of depression over a two year period? A test of the mental health promotion and protection hypotheses. Journal of Affective Disorders, 270, 136-142. https://doi. org/10.1016/j.jad.2020.03.056

Kline, R.B. (2010). Principles and practice of structural equation modeling (3rd edn.). New York, NY: The Guilford Press.

Kyriacou, C. (2011). Teacher stress: From prevalence to resilience. In J. Langan-Fox \& C.L. Cooper (Eds.), Handbook of stress in the occupations (pp. 161-176). Cheltenham and Northampton, MA: Edward Elgar Publishing.
Lazarus, R.S. (1993). Coping theory and research: Past, present, and future. Psychosomatic Medicine, 55(3), 234-247. https://doi.org/10.1097/00006842 199305000-00002

Lazarus, R.S., \& Folkman, S. (1984). Stress, appraisal, and coping. New York, NY: Springer.

Lee, A.N., \& Nie, Y. (2014). Understanding teacher empowerment: Teachers' perceptions of principal's and immediate supervisor's empowering behaviours, psychological empowerment and work-related outcomes. Teaching and Teacher Education, 41, 67-79. https://doi.org/10.1016/j.tate.2014.03.006

Liebenberg, K., \& Hattingh, C. (2017). ' $n$ Evaluering van opvoedermoreel in skole in Wellington. LitNet Akademies, 14(3), 661-717.

Liu, X., Zhao, Y., Li, J., Dai, J., Wang, X, \& Wang, S. (2020). Factor structure of the 10 item Perceived Stress Scale and measurement invariance across genders among Chinese adolescents. Frontiers in Psychology, 11, 537. https://doi.org/10.3389/ fpsyg.2020.00537

Maier, S.F., \& Seligman, M.E.P. (2016). Learned helplessness at fifty: Insights from neuroscience. Psychological Review, 123(4), 349-367. https://doi.org/10.1037/ rev0000033

Mansfield, C.F., Beltman, S., Broadley, T., \& Weatherby-Fell, N. (2016). Building resilience in teacher education: An evidenced informed framework. Teaching and Teacher Education, 54, 77-87. https://doi.org/10.1016/j.tate.2015.11.016

McCarthy, J. (2007). A framework for healing from loss: A further integration of psychodynamic and social work theory. Journal of Human Behavior in the Socia Environment, 14(3), 45-79. https://doi.org/10.1300/J137v14n03_03

McCarthy, C.J., Lineback, S., Fitchett, P.G., Lambert, R.G., Eyal, M., \& Boyle, L.H. (2017) The role of culture and other contextual factors in educator stress. In T.M McIntyre, S.E. Mclntyre, \& D.J. Francis (Eds.), Educator stress: An occupationa health perspective (pp. 157-177). Cham: Springer International Publishing.

Meyer, J.P., \& Morin, A.S. (2016). A person-centered approach to commitment research: Theory, research, and methodology. Journal of Organizational Behavior 37(4), 584-612. https://doi.org/10.1002/job.2085

Montgomery, C. (2017). Development and testing of a theoretical-empirical model of educator stress, coping and burnout In T.M. McIntyre, S.E. McIntyre, \& D.J. Francis (Eds.), Educator stress: An occupational health perspective (pp. 181-196). Cham: (Eds.), Educator stress: An occupatior
Springer International Publishing.

Montgomery, C., \& Rupp, A.A. (2005). A meta-analysis for exploring the diverse causes and effects of stress in teachers. Canadian Journal of Education, 28(3), 458-486. https://doi.org/10.2307/4126479

Moos, R.H., \& Schaefer, J.A. (1993). Coping resources and processes: Current concepts and measures. In L. Goldberger \& S. Breznitz (Eds.), Handbook of stress: Theoretical and clinical aspects (2nd edn., pp. 234-257). New York, NY: The Free Press.

Morin, A.J.S., McLarnon, M.J.W., \& Litalien, D. (2020). Mixture modeling for organizational behavior research. In Y. Griep, \& S.D. Hansen (Eds.). Handbook on the temporal dynamics of organizational behavior (pp. 351-379). Cheltenham: Edgar Elgar Press.

Muthén, L.K., \& Muthén, B.O. (1998-2020). Mplus user's guide (7th edn.). Los Angeles, CA: Muthén \& Muthén.

Nasser, F.A.A. (2015). Teacher stress and coping: The role of personal and job characteristics. Procedia - Social and Behavioral Sciences, 185, 374-380. https:// characteristics. Procedia- Social and B
doi.org/10.1016/j.sbspro.2015.03.415

$\mathrm{Ng}$, T.W., \& Sorenson, K.L. (2008). Towards a further understanding of the relationships between perceptions of support and work attitudes: A meta-analysis. Group and Organization Management, 33(3), 243-268. https://doi.org/10.1177/ 1059601107313307

Park, C.L. (2011). Meaning, coping and health and well-being. In S. Folkman (Ed.), The Oxford handbook of stress, health and coping (pp. 227-241). New York, NY: Oxford University Press.

Park, J., \& Kim, T. (2009). Do types of organizational culture matter in nurse job satisfaction and turnover intention? Leadership in Health Services, 22(1), 20-38. https://doi.org/10.1108/17511870910928001

Rautenbach, C., \& Rothmann, S. (2017). Psychometric validation of the Flourishing-atWork Scale-Short Form (FWS-SF): Results and implications of a South African study. Journal of Psychology in Africa, 27(4), 303-309. https://doi.org/10.1080/1 4330237.2017.1347748

Raykov, T. (2009). Evaluation of scale reliability for unidimensional measures using latent variable modeling. Measurement and Evaluation in Counseling and Development, 42(3), 223-232. https://doi.org/10.1177/0748175609344096

Redelinghuys, J.J., \& Rothmann, S. (2020). Exploring the prevalence of workplace flourishing amongst teachers over time. SA Journal of Industrial Psychology, 46(0), a1764. https://doi.org/10.4102/sajip.v46i0.1764

Redelinghuys, J.J., Rothmann, S., \& Botha, E. (2019). Workplace flourishing: Measurement, antecedents and outcomes. SA Journal of Industrial Psychology 45(0), a1549. https://doi.org/10.4102/sajip.v45i0.1549

Rothmann, S. (2013). From happiness to flourishing at work: A Southern African perspective. In M.P. Wissing (Ed.), Well-being research in South Africa, crosscultural advances in positive psychology (pp. 123-151). Dordrecht: Springer.

Rothmann, S., Jorgensen, L.I., \& Marais, C. (2011). Coping and work engagement in selected South African organisations. SA Journal of Industrial Psychology/SA Tydskrif vir Bedryfsielkunde, 37(1), Art. \#962, 11 pages. https://doi.org/10.4102/sajip. v37i1.962

Rothmann, S., Van Zyl, L.E., \& Rautenbach, C. (2019). Measuring flourishing @ work interventions: The development and validation of the Flourishing-at-Work Scale. interventions: The development and validation of the Flourishing-at-Work Scale. In L.E. Van Zyl \& S. Rothmann (Eds.), Positive psychological interventions.
Approaches to capacity development within multi-cultural contexts (Volume 2; pp. 217-240). Cham: Springer. 
Schonfeld, I.S., Bianchi, R., \& Luehring-Jones, P. (2017). Consequences of job stress for the psychological well-being of teachers. In T.M. McIntyre, S.E. Mclntyre, \& D.J.
Francis (Eds.), Educator stress: An occupational health perspective (pp. 55-75). Francis (Eds.), Educator stress: An occup
Cham: Springer International Publishing.

Seery, M.D., Holman, E.A., \& Silver, R.C. (2010). Whatever does not kill us: Cumulative lifetime adversity, vulnerability, and resilience. Journal of Personality and Social Psychology, 99(6), 1025-1041. https://doi.org/10.1037/a0021344

Sisodia, R., \& Gelb, M.J. (2019). The healing organization: Awakening the conscience of business to help save the world. Broadway, NY: HarperCollins Leadership.

Sjöberg, A., \& Sverke, M. (2000). The interactive effect of job involvement and organizational commitment revisited: A note on the mediating role of turnove intention. Scandinavian Journal of Psychology, 68, 653-663. https://doi. org/10.1111/1467-9450.00194

Skaalvik, E.M., \& Skaalvik, S. (2011). Teacher job satisfaction and motivation to leave the teaching profession: Relations with school context, feeling of belonging, and emotional exhaustion. Teaching and Teacher Education, 27(6), 1029-1038. https://doi.org/10.1016/j.tate.2011.04.001

Spreitzer, G.M., Lam, C.F., \& Fritz, C. (2010). Engagement and human thriving Complementary perspectives on energy and connections to work. In A.B. Bakker \& M.P. Leiter (Eds.), Work engagement: A handbook of essential theory and research (pp. 132-146). Psychology Press.

Spurk, D., Hirschi, A., Wang, M., Valero, D., \& Kauffeld, S. (2020). Laten profile analysis: A review and 'how to' guide of its application within vocational behavio research. Journal of Vocational Behavior, 120, 103445. https://doi.org/10.1016/j. jvb.2020.103445

Steger, M.F., Dik, B.J., \& Duffy, R.D. (2012). Measuring meaningful work: The Work and Meaning Inventory (WAMI). Journal of Career Assessment, 20(3), 322-337. https://doi.org/10.1177/1069072711436160

Taylor, S.E. (2011). Affiliation and stress. In S. Folkman (Ed.), The Oxford handbook of stress, health and coping (pp. 86-100). New York, NY: Oxford University Press.

Tomasulo, D, (2020). Learned hopefulness: The power of positivity to overcome depression. Oakland, CA: New Harbinger Publications.
Tran, V.D. (2016). Coping styles with student misbehavior as mediators of teachers' classroom management strategies. International Journal of Higher Education, 5(1), 1-10. https://doi.org/10.5430/ijhe.v5n1p1

Travers, C. (2017). Current knowledge on the nature, prevalence, sources and potential impact of teacher stress. In T.M. McIntyre, S.E. McIntyre, \& D.J. Francis (Eds.), Educator stress: An occupational health perspective (pp. 23-54). Cham: Springer.

Treglown, L., Zivkov, K., Zarola, A., \& Furnham, A. (2018). Intention to quit and the role of dark personality and perceived organizational support: A moderation and mediation model. PLoS One, 13(3), e0195155. https://doi.org/10.1371/journal. pone. 0195155

Tugade, M.M., \& Fredrickson, B.L. (2004). Resilient individuals use positive emotions to bounce back from negative emotional experiences. Journal of Personality and Social Psychology, 86(2), 320-333. https://doi.org/10.1037/00223514.86.2.320

Vaughn, A.A., \& Roesch, S.C. (2003). Psychological and physical health correlates of coping in minority adolescents. Journal of Health Psychology, 8(6), 671-683. https://doi.org/10.1177/13591053030086002

Wang, A.W., Cheng, C., Chang, C., Chen, D., Chen, S., Shieh, V. et al. (2018). Does the factor structure of the Brief COPE fit different types of traumatic events? A test of measurement invariance. European Journal of Psychological Assessment, 34(3), 162-173. https://doi.org/10.1027/1015-5759/a000321

Wang, J., \& Wang, X. (2020). Structural equation modeling: Applications using Mplus. Wiley.

Watlington, E., Shockley, R., Guglielmino, P., \& Felsher, R. (2010). The high cost of leaving: An analysis of the cost of teacher turnover. Journal of Education Finance, 36(1), 22-37. https://doi.org/10.1353/jef.0.0028

Weiten, W. (2013). Psychology: Themes and variations (9th edn.). Wadsworth, $\mathrm{OH}$ : Cengage Learning.

West, S.G., Taylor, A.B., \& Wu, W. (2012). Model fit and model selection in structura equation modeling. In R.H. Hoyle (Ed.), Handbook of structural equation modeling (pp. 209-231). New York, NY: The Guilford Press. 